\title{
Evolution and the Relationship Between Brain and Mind States
}

\author{
Juan S. Gómez-Jeria, Lic. Q. \\ Carlos Madrid-Aliste \\ University of Chile
}

ABSTRACT. We discuss the phylogenetic basis of states of consciousness, and present the central theses of monism and dualism, in which near-death experiences (NDEs) enjoy very different ontological statuses. Next, we summarize the evolution of the genus Homo, with emphasis on neuroanatomical changes, and define brain and consciousness states. Data suggest that consciousness states are produced by brain states. We address the problem of states of consciousness in other species because consciousness states seem to emerge from a phylogenetic continuum, and analyze problems connected with verbal reports of internal experiences. Finally, we examine NDEs as brain states/consciousness states, and conclude that we need further study of elements appearing in each NDE with their order of appearance. We discuss problems in the relationship between brain states and consciousness states, and conclude that science does not need a paradigm shift to deal with NDE data.

Every word and every brain,

And our ancient family line ... .

Everything must come to death.

-Michelangelo Buonarotti, Sonnet, 16th century

When a new phenomenon is accepted as being real, a first step in its study is its observation and classification. At this stage, speculation about its origin and composition is normal. Sometimes this stage

Juan S. Gómez-Jeria, Lic. Q., is Associate Professor of Quantum Chemistry and Philosophy of Science at the Faculty of Sciences, University of Chile. Carlos MadridAliste is an undergraduate student of the Faculty of Sciences of the University of Chile. This work has received financial support from the University of Chile (Grant Q-3064) and from the International Association for Near-Death Studies through their Small Grants Program. We gratefully acknowledge the very helpful comments of Prof. Dr. Bruce K. Cassels. Reprint requests should be addressed to Prof. Gomez-Jeria at the Faculty of Sciences, University of Chile, Casilla 653, Santiago, Chile. 
is never overcome. More often, statistics are used to mask the conceptual poverty related to lack of knowledge of the phenomenon. In still other cases, the discovery of the phenomenon and some predictions about its behavior are accepted as sufficient. For a scientific explanation, however, it is necessary to construct a hypothetical-deductive system, which can be checked against available evidence; naturally, this demands some simplification, or model creation. In addition, a phenomenon should be placed within the physical world to study it more adequately.

In this article we shall present some thoughts about human evolution and its link with the appearance of more and more complex mental phenomena. Then, near-death experiences (NDEs) will be discussed within this framework. We intend this article as a basis to open an exchange of ideas among interested people.

\section{Monism and Dualism}

All ideas about the relationships between the brain and the mind can be grouped into two main streams of thinking: monism and dualism. In very general terms, the former holds that all things can be reduced to one class of substance, while the second maintains that brain and mind are not mutually reducible. Monism does not assign ontological freedom to the mind, but considers it as a product of the brain. There are at least five monist and five dualist positions about $\mathrm{mind} /$ brain relationships (Bunge, 1980). Only dualist positions permit the possibility of "something," such as a soul, spirit, or astral body, "going out" of the body and having body-independent out-of-body or near-death experiences. Clearly, NDEs enjoy a very different ontological status in monism and dualism.

A position regarding this problem must be able to survive the scrutiny of independent observers. However pleasant any pattern of thinking may be, it must be rejected as soon as an observation appears for which there is no place in it. If such a procedure is not used, any position is allowed. This can lead to arguments ad ignorantium: a proposition is considered true simply on the basis that it has not been proved false, such as acceptance of unidentified flying objects or ghosts, or an extremely long list of analogous beliefs. In the following we shall present and comment on scientific data that can be verified by any reader, and that will help us to decide whether monism or dualism are to be taken seriously. 


\section{Human Evolution and Brain States}

The first stage in this work must be some words about how we Homo sapiens sapiens evolved. We may consider Homo sapiens sapiens as the successful result (a work in progress) of a certain number of variations of a genetic pool that produced other variations that either survived or did not. The phylogenetic changes leading to Homo sapiens are more or less known. One model suggests the following steps, which could of course be modified with new scientific evidence:

About 15 million years ago (all these dates are approximate), a line leading to the present-day orangutan separated from the line leading to genus Homo (see Moyà Solà and Köhler, 1993). About 9 million years ago, another branch leading to the modern gorilla evolved, and about 5 million years ago, the line leading to the modern chimpanzees emerged. About 4 million years ago, Australopithecus afarensis appeared, surviving about 1 million years. About 2 to 3 million years ago the Homo line diverged from Australopithecus and divided into several species; this seems to have occurred in Africa (Schrenk, Bromage, Betzler, Ring, and Juwayeyi, 1993; Wood, 1992a, 1992b).

About 1 million years ago, Homo erectus migrated to Eurasia. The descendants of this migration are Homo sapiens neanderthalensis. About 250,000 years ago, in Africa and probably within a very restricted population of Homo erectus, the ancestor of Homo sapiens sapiens appeared. About 100,000 years ago, our ancestors migrated to Eurasia (see Gibbons, 1993). The last Homo sapiens neanderthalensis disappeared about 35,000 years ago (Stringer, 1992: Valladas, Vandermeersch, and Bar-Yosef, 1988; Wolpoff and Frazer, 1992). After this, Homo sapiens sapiens migrated throughout the rest of the world and eventually produced civilization as we know it (Andrews, 1992; Cann, Stoneking, and Wilson; 1987; CavalliSforza, Piazza, Menozi, and Mountain, 1988; Conroy, Pickford, Senut, Van Couvering, and Mein, 1992; Hill, Ward, Deinoi, Curtis, and Drake, 1992; Lewin, 1992; Maddison, 1991; Mercier, Valladas, Joron, Reyss, Leveque, and Vandermeersch, 1991; Simons, 1989; Stringer, 1990; Stringer and Andrews, 1988; Vigilant, Stoneking, Harpending, Hawkes, and Wilson, 1991; Walker, Leakey, Harris, and Brown, 1986; Wolpoff, 1984; Wolpoff and frazer, 1992; Wood, 1992a, 1992b). 
Steven Stanley (1992) proposed an ecological theory for the origin of the genus Homo. He suggested that about 2.5 million years ago the evolution of large-brained early Homo followed closely the global climatic changes signaling the onset of the modern Ice Age. At this time, forests shrank and grassy habitats expanded, forcing some australopithecine populations to abandon arboreal activities. It is probable that a single fully terrestrial population (or an entire bottlenecked species) of australopithecines evolved into Homo (Stanley, 1992). Stanley noted that this evolution under a crisis situation entailed only a restriction of the existing behavior and not a sudden change or mutation. The progressive encephalization followed from selection pressure, resulting primarily from an extension of the high fetal growth rate into the postnatal stage. This delayed development seems to be the reason why humans have the longest interval of helplessness among all mammals (Stanley, 1992; see also Foley and Lee, 1989; Gibbons, 1993; Schrenk, Bromage, Betzler, Ring, and Juwayeyi, 1993).

During this time, the brain underwent a process of change such that one of the brain's hemispheres came to control spatial behaviors, while the other was involved in the regulation of linguistic functions. This differentiation, coupled to the noteworthy fact that at present most people are right-handed and have language represented in the left hemisphere of the brain, needs an explanation. Right-handedness developed independently and prior to language; in fact, there is evidence to suggest that 2 million years ago hominids were righthanded.

Given that our primate ancestors were ambidextrous and that both brain hemispheres processed information in a symmetrical way, a biasing mechanism based on survival has been proposed, in which hominids were more likely to survive if they fought with the right hand, while the left one protected the heart. With time, a male right-handed population was selected. In the case of females, the fact that young infants are calmed when they hear a heart's beating helped right-handed females to survive predators (see MacLean, 1990). Then, natural selection led to the regulation of dexterity by the left hemisphere, while the right one dealt with the regulation of manipulative spatial skills. This does not preclude the possibility that, as hominids lived in groups, some left-handed people survived.

Language and spatial behavior require a multimodal convergence. Furthermore, language must follow the appearance of some internal 
representation of the external milieu. If the developing language system has greater survival value when connected with the mechanisms controlling dexterity, there will be a bias favoring the left hemisphere. On the other hand, from the point of view of hardware, it will be advantageous for the tongue, a midline organ with bilateral innervation, to receive its commands from a single hemisphere. These two coupled effects lead to the above mentioned fact. The nondominant hemisphere is the neurobiological link with the primate path because its changes have been a matter only of degree.

The conclusion is therefore that evolutionary pressures led to modifications in the brain of hominids allowing them to deal better with internal representation and motor manipulation of the external world and its objects (Arensburg and Tillier, 1990; Beynon and Dean, 1988; Brain and Sillen, 1988; Conroy, Vannier, and Tbbias, 1990).

The anatomical structures involved in arousal and attention, the basic components of consciousness states, are phylogenetically old and correspond to the nuclei giving origin to the cholinergic, noradrenergic, serotonergic, and histaminergic projections to the brain cortex. The stimulation of these projections has in common an optimization of the signal-to-noise ratio, in such a way as to permit a more accurate transmission of the information arriving to the cortex (McCormick, 1989).

Several studies have shown the remarkable development of the human association cortices in volume and complexity of organization. It has been suggested that the functioning of these structures is the basis of behavior that is properly human (Connolly, 1950; Crosby, 1982; Pearson and Pearson, 1976; Stephan and Andy, 1969). In the normal conscious state, with sensory input kept at a minimum, there is high activity in the frontal cortex, and less in post-central and temporal regions (Ingvar, 1979). It has been suggested that the frontal activity in these conditions comes from a simulation of behavior, i.e., "an inner anticipatory programming of several alternative behavioral modes prepared to be used depending upon what will happen" (Ingvar, 1979, p. 21). This frontal activity can be conscious or unconscious.

An example of conscious activity came from studies of the neuroanatomical correlates of anticipatory anxiety (Reiman, Fusselman, Fox, and Raichle, 1989). In these studies, apart from a significant increase in bilateral temporal lobe activity, related to anxiety and panic attacks, there is an additional increase of activity in the bilateral temporofrontal regions near the anterior aspect of the lat- 
eral sulcus. This last activity could be related to an analysis of the approach to the anxiety-causing stimulus.

Furthermore, in patients with obsessive-compulsive disorder, abnormalities are observed that involve the orbital frontal cortex, frontal white matter, cingulate gyrus, and lenticular nuclei of the right hemisphere (Garber, Ananth, Chiu, Griswold, and Oldendorf, 1989); these areas are components of the frontal-limbic pathways. Assuming that in these patients the left hemisphere is the verbal one, this abnormal activity could correspond to an unconscious activity in which a given algorithm, the one leading to the obsessive-compulsive behavior, is continuously processed, leading to obsessive thinking, and executed without verbal control, producing compulsive behavior. This could imply that the nonverbal hemisphere might influence the verbal one not only for written or verbal responses, but also for motor behavior (Gazzaniga, 1985).

According to Paul Green, Stephan Hallett, and Mick Hunter (1983), the positive symptoms of schizophrenia may come from an abnormal awareness of the right hemisphere's activity by the left hemisphere. Also, the anterior corpus callosum, which connects the right and left frontal lobes, seems to be involved in higher order cognition (Sidtis, Volpe, Holtzman, Wilson, and Gazzaniga, 1981). Moreover, it has been suggested that the most differentiated areas of the prefrontal cortex, which are not connected with the limbic system, may be involved in complex discrimination and spatial functions (Barbas and Pandya, 1989). In agreement with the above, we think that the neocortical development of the association areas, especially the prefrontal ones, is the basis of self-consciousness (Sanidos, 1969). Our next step is to discuss a way of representing brain functioning.

\section{Brain States}

First, it is necessary to explain what we mean by "brain state." Taking the neuron as the simplest unit of the central nervous system, we have at least three ways of describing brain functioning: as a set of neurons, as a set of neuronal groups, or as a neuronal network. Let us select, for example, the neuronal level of description. We must select one or more neuronal variables to describe their function. For the purpose of this discussion we shall select the firing state. Then, for neuron $n_{i}$ we shall have two possible states of $s_{i}: s_{i}=0$ when the 
neuron is not firing and $s_{i}=1$ when it is. If we denote by $N$ the total number of neurons in the brain, the jth state of the system will be described by a time-dependent vector $\overrightarrow{\mathrm{S}}_{j}^{\mathrm{B}}=(1,2, \ldots, \mathrm{N}, \mathrm{t})$ $=\left(s_{1}, s_{2}, \ldots, s_{N}\right)$, where $B$ refers to brain and the s's are the actual values for each neuron. Note that while it is a technological impractibility at this time, there is no scientific principle forbidding the $a$ priori knowledge of the state of each neuron. Considering that each neuron is independent, we shall have an $\mathrm{N}$-dimensional discontinuous space, in which each point corresponds to a possible state of the system. For example, the state described by the vector $S_{0}(1,2, \ldots$, $\mathrm{N}, \mathrm{t})=(0,0, \ldots, 0)$ corresponds to that in which no neuron is firing at time t. If this state persists for, say 29 minutes, the brain may be considered as dead.

Using phase space formalism, we can describe the state of the system called brain (B) by the values of $i$ variables $b_{1}, b_{2}, \ldots, b_{i}$, which are linearly independent. To this system we shall couple a Euclidean i-dimensional space, $\Gamma$, whose points are determined by the Cartesian coordinates $\left\{b_{j}\right\}$. Then, for each possible state of B there will correspond a point in $\Gamma$ that is called the image point of $B$. The whole space $\Gamma$ will be called the brain states space. The motion of the image point in the brain states space represents therefore the change of state of B. Note that this description is a purely neuronal one.

\section{Mind States}

The definition of a mind state is a rather complex subject. An examination of the literature clearly indicates that topics such as mind, consciousness, self, self-consciousness, the unconscious, and related themes seem to have different meanings for different people. There is no doubt that this area needs to be cleaned conceptually. Here we shall speak of consciousness and we shall consider it as a primitive concept, though this does not preclude its a posteriori elucidation.

A statement about consciousness must be made to open the discussion. What could the general characteristics of consciousness states be? We have several candidates for answers to this question: for example, that they are private, that they have an intentional content, that we are aware of them, or that they employ internal language and/or images. 
The most obvious characteristic of consciousness is its continuous stream, never being the same from moment to moment (James, 1892/1984). The continuous change of consciousness, and the existence of radically different modes of mental working, led to the concept of "states of consciousness." Following Charles Tart, we shall define the normal state of consciousness as follows: "For any given individual, his normal state of consciousness is the one in which he spends the major part of his waking hours" (Tart, 1969, p. 1). We refer to normal individuals and we assume that within this set of human beings the normal state of consciousness is approximately the same. The other states can be reached from the normal state of consciousness, and we shall refer to them as "alternate states of consciousness," instead of Tart's term "altered states of consciousness."

Seeking a list of alternate states of consciousness in the literature yields a surprising variety of them, including lucid dreams, daydreaming, meditation, hypnosis, trance, ecstasy, stupor, coma, and states labeled mystical, hypnagogic, psychotic, creative, drug-induced, hyperalert, lethargic, hysteric, fragmented, regressive, expanded, and released (Bourgignon and Evascut, 1977; Fischer, 1971; Globus, Maxwell, and Savodnik 1977; Tart, 1969; Valle and von Eckartsberg, 1981; White, 1972; Zaehner, 1972; Zimberg, 1977). This apparent variety exists because of the lack of a formal theory defining the different states of consciousness and their interconnections.

There have been some interesting theoretical developments pointing to such a theory but, as far as we know, a theory does not yet exist (Drab, 1981b; Fischer, 1971; Marsh, 1977; Saavedra-Aguilar and Gómez-Jeria, 1987; Tart, 1969, 1972, 1977). Some "permanent" psychiatric states, such as autism or catatonic schizophrenia, can be viewed as stable areas in the consciousness state space. On the other hand, states of consciousness such as NDEs, out-of-body experiences, and drug-induced states may be viewed as unstable states that can be reached from the normal one and that decay after some time. This passage between states is equivalent in the formalism to a movement in the state space.

For consciousness $(\mathrm{C})$, we may also apply the phase space formalism; $j$ linearly independent variables $\left\{c_{k}\right\}$, a $j$-dimensional consciousness state space, $\Theta$, and so on. This will be a purely consciousness/language description. Nevertheless, we are confronted with the major problem of finding the variables to be used in the construction of $\Theta$. Variables such as attention, memory of several kinds, concentration, and awareness may be used, but only after con- 
ceptual elucidation of these concepts. This is an open field of research.

\section{The Relationship Between Brain States and Consciousness States}

The separate definitions of the brain state space and consciousness state space do not represent a dualistic position, but rather our temporary ignorance of the equivalence between them. We must elucidate two relevant questions: the relationship between $\operatorname{Dim}(\Gamma)$ and $\operatorname{Dim}(\Theta)$ and the relationship between the movement of the image points in both spaces. The former cannot be determined theoretically, but rather by considering all relevant data regarding brain functioning and consciousness models. These two spaces are not independent but are equivalent. Also, the variation of one variable in one space can be accounted for by the variation of one or several variables in the other. These variations may or may not be linear.

At this point, we must consider that the normal state of consciousness is not a point in the consciousness state space, but a hypervolume defined by the minimal and maximal values of each variable varying in this state. External fluctuations, such as those due to drugs, panic, shocks, sensory deprivation, torture, or asceticism, may lead the system rather far from a not very stable state. Also, there is a dynamic equilibrium between the brain and the environment: slow changes in the latter will produce slow changes in the former. These changes compel the system to explore an "area" around the position of stable equilibrium.

This hypervolume limits with some alternate states of consciousness, which are geometrically close to the normal state of consciousness. This does not mean that we can move from the normal state to all the neighboring alternate states with the same probability; in fact, there will be some alternate states that are more accessible due to the possibility that some variables vary more easily than others, creating more likely paths. For this reason some alternate states of consciousness, like the so-called mystical one(s), are reached by fewer people than others such as out-of-body or tunnel alternate states.

The problems arising with the definition of brain states and the differences between mental-state sentences and brain-state sentences have been discussed by other (Armstrong, 1973; Raab, 1965; Wilkes, 1980) Considering the present knowledge in brain sciences and the 
considerable ambiguity in the verbal description of consciousness states, we need to employ a rational and cautious approach to overcome these difficulties.

In this regard, we may employ Jeffrey Gray's approach to the analysis of anxiety (Gray, 1987): a certain internal state is called "anxiety" in consciousness language, and in brain language this state is probably located somewhere inside the limbic system. Therefore, we may consider two forms of description for anxiety: a description of the psychological processes that are modified by the anxiety-suppressing drugs, that is, a description of the psychology of anxiety; and a description of the neuronal processes modified by these drugs, that is, a neurobiological description of anxiety (Gray, 1987).

The integration of both descriptions will produce a neuropsychology of anxiety erasing the artificial brain/consciousness division. We must stress that we are not describing two different phenomena but are employing two different levels of abstraction. This approach was used in our neurobiological model of NDEs (Gómez-Jeria and SaavedraAguilar, 1994; Saavedra-Aguilar and Gómez-Jeria, 1989a, 1989b).

The question that is still unanswered is whether a physical relationship between brain and consciousness exists. Let us first examine dualist positions. If we accept that consciousness is a nonphysical thing (substance dualism) or that the brain has a set of nonphysical properties (property dualism), or any other possible dualist position, then we need to answer scientifically when nonphysical consciousness or nonphysical brain properties appeared. We may say as a provisional answer that they appeared at a certain stage " $A$ " of human evolution; for example, that they appeared in Australopithecus or in Homo habilis. The next question to answer is why they appeared at this stage and not at a previous one. The only reasonable scientific answer would be because at stage " $\mathrm{A}$ " the physical structures of the central nervous system made it possible. This implies a causal relationship between physical structure and "nonphysical mind" or "nonphysical brain properties." Unless we hold that physical structure at stage "A" involved a "kind of connection"-which must finally must be of a physical nature--between the physical body and "nonphysical mind" lying in another "plane"-a nonscientific answer that also maintains a causal brain/nonphysical mind relationship but allows the existence of souls, heavens, and hells-we must conclude that when physical structures disappear, "nonphysical minds" or "nonphysical brain properties" also disappear. 
Stage " $A$ " could be moved back to more distant ancestors, but that would lead to interesting problems like the existence of consciousness states in whales, chickens, or proconsuls. This reductio ad absurdum argument will always lead to the general conclusion that consciousness states are produced by brain states, and that human states exist because of the particular form of brain evolution attained in Homo sapiens sapiens. Within this context, Kenneth Arnette's (1992) attempt to revive dualism by using NDE data is untenable. On the other hand, the emergence of consciousness through evolution leads to the natural question of the existence of consciousness states in other species, since brain states exist because of neuronal functioning.

\section{Consciousness States in Other Species}

The existence of phylogenetic continuity in some mental processes, such as world perception, is expected. This hypothesis leads naturally to the question of the existence of consciousness states in species close to us in the evolutionary line, like the great apes. The genetic distance between chimpanzees and humans is remarkably small (King and Wilson, 1975).

If the great apes have consciousness states, it is necessary that they be aware of their internal states and be able to communicate them, though it is not necessary that their internal experiences should be similar to ours.

Determining whether apes have consciousness states requires a knowledge of how these species experience the world: their perceptions, thoughts, and feelings (Mason, 1976). As James Gibson (1966, p. 5) pointed out, "the perceptual systems, including the nerve centers at various levels up to the brain, are ways of seeking and extracting information about the environment from the flowing array of ambient energy." Taking behavior as the final point of an information processing sequence (Mason, 1976), our first step in the analysis of consciousness states in great apes involves a comparison of sensory capacities.

Humans and great apes have virtually identical color vision, while humans have an increased sensitivity to low frequency sounds and a reduced sensitivity to high frequency ones (King and Fobes, 1974). Regarding olfaction, humans show an important loss of olfaction as 
a mode of communication, accompanied by changes in olfactory anatomical correlates (King and Fobes, 1974; Stephan and Andy, 1969).

Regarding brain anatomy, comparative studies of the Sylvian fissure have shown that it is longer in the left hemisphere of the human brain than in the right, and that chimpanzees show this same asymmetry to a lesser degree (Yeni-Kanshian and Benson, 1976). If functional asymmetries are associated with anatomical asymmetries, then asymmetry in brain functioning is not limited to humans. Despite the above, a comparative study of neocortical development in insectivores and primates showed (Stephan and Andy, 1969) that the differences between the indices of cortical progression in chimpanzees and humans are greater than between chimpanzees and insectivores, showing the great neocortical development achieved by humans in relation to apes; and that gorillas, who are well known to have a social behavior, have a comparatively low cortical index compared to other apes.

On the other hand, experimental evidence has shown that chimpanzees can respond to relations among elements and to specific attributes of elements; classify objects according to their physical properties; distinguish the physical properties of the sign of an object from the properties of the object signified; carry out intermodal integration; work with functional categories; remember selectively; anticipate the consequences of their own actions and, to a lesser degree, the actions of others; reconstitute concepts, as in "ducks = water birds"; learn by observation; and recognize their own mirror reflections (Beck, 1974; Fouts, 1974; Gallup, 1968, 1970, 1977; Mason, 1976).

To further develop our analysis, we must say some words about communication, self-recognition, and self-consciousness. It has been suggested that "The capacity for self-recognition [in mirrors], although influenced by learning, is predicated on a sense of identity," (Gallup, 1977, p. 334) and that the mirror is only a means of objectifying self-concept. Self-recognition implies a certain degree of selfconsciousness, or self-awareness, but there are no studies directed at knowing the degree of self-consciousness in great apes or whether self-consciousness in apes is a permanent state or is only evoked by random circumstances.

The studies of communication between humans and great apes still have not provided conclusive results (Fouts, 1974; Mounin, 1974, 1976; von Glassersfeld, 1974). William Mason (1976) suggested that, at the level of vocalized language, the difference between humans 
and great apes is qualitative, while at the level of concept formation, that difference is only quantitative. Of interest also is the suggestion that the basis of language is not unique to language itself but is also the basis for other behaviors (Fouts, 1974). Finally, Benjamin Beck (1974) pointed out that since language is well suited for observation learning, and chimpanzees' proficient tool behavior is due mainly to observation learning, it is not strange that they show an interesting language ability.

If we accept Mason's premise that "All behavior that is guided by sensory information, that is, most of the behavior that interests us, implies some type of schema or functional 'image' of the environment" (1976, p. 284), and if we consider the above information, it would not be too far-fetched to suggest that if any species other than humans have consciousness states, then chimpanzees and orangutans are the best candidates.

Be that as it may, it seems conceivable that most human consciousness states are radically different from the consciousness states of the great apes. The main reasons are our high degree of self-consciousness and the internal and external use we make of verbal language. In this respect, NDEs are typically human.

Nevertheless, the above discussion was necessary in order to place these experiences within the general framework of consciousness states that seems to emerge from a phylogenetic continuum. On the other hand, as speaking mammals we use language to report our internal experiences. In the next section we mention some problems related to language use.

\section{Verbal Reports of Internal Experiences}

The role of verbal (or written) language is fundamental in the research of alternate states of consciousness. Verbal systems, developed from the perceptual world, sometimes dissociate from it, becoming isolated within their own reality and acquiring truth value per se. As an example, we may cite the cases of some religious, political, and economic theories, which are verbal constructions devoid of any scientific base, yet which exist and propagate through time. In some moments of world history their proponents have had the opportunity to implement their models and have found that reality was different from what their models predicted. Intelligent people usually try to adapt models to reality; nevertheless, the existence of mass murder, 
population deportation, concentration camps, and general economic failure shows that people sometimes insist on trying to adapt reality to their models.

On a smaller scale, verbal reports do not generally describe what a subject has perceived. For example, in chronic schizophrenia, the initial verbal descriptions of hallucinations do not correspond to what individuals perceived. Interestingly, in normal individuals the secondary elaboration of the hallucinatory state may result in hallucinations, illusions, eidetic imagery, or hypnagogic states that are related to their actual needs and wishes.

Furthermore, the use of hallucinogenic drugs causes an impairment of learning and retention of connected verbal material, especially of the neutral kind, an effect restricted to accuracy (Paul, 1964). Also, the individual has better recall of experiences that are likely to occur in the normal state of consciousness (Linton, Langs, and Paul, 1964). Finally, written reports of the same experience by different persons show clear internal consistency (Oxman, Rosenberg, Schnurr, Tucker, and Gala, 1988).

Dissonance is defined as

a negative state of psychological tension aroused when the individual holds two cognitions that are mutually inconsistent. Dissonance arousal motivates the individual to reduce dissonance by changing one or both of the inconsistent cognitions. (Kiesler and Pallak, 1976).

In general, it is demanded that attitude and behavior be consistent. Let us suppose that someone believing in life after death has a NDE in which he or she sees lights and figures. The experiencer will naturally interpret light as "heavenly lights" and the figures as "sacred beings," such as angels or gods. For this reason the researcher must try to get information from experiencers before it is further elaborated verbally (see for example Gómez-Jeria, 1993). Furthermore, the possibility that the nonverbal hemisphere influences the verbal one for spoken or written responses must not be ruled out (Gazzaniga, Holtzman, and Smylie, 1987; Sidtis, Volpe, Holtzman, Wilson, and Gazzaniga, 1981).

The need for keeping scientific objectivity in near-death studies is stressed by its particular nature. In fact, if a near-death researcher falls into parochial attitudes, he or she will be exposed to two dangers: interacting with NDErs in a way leading to the so-called "selffulfilling prophecy" (Jones, 1986), or becoming lost in an unreal but self-consistent verbal world. This kind of deviation is not new in hu- 
man history. Long ago it was said that "after inventing their systems, they accumulate dispersed texts and names and transpose them from their natural sense to a forced one" (Iranaeus, ca. 180).

\section{Brain States and NDEs}

In light of the above considerations, we consider NDEs as a consciousness (purely psychological description)/brain (purely neurobiological description) state. We fully agree with Kevin Drab (1981a, 1981b) that the NDE is constituted by a variety of alternate states of consciousness, of discrete configurations.

In his study of the tunnel experience, Drab noted that "The majority of cases experienced no preceding [experiential] elements or sense of logical transition to their TEs [tunnel experiences]" (Drab, 1981a, p.137). This is also true for NDEs, in which one finds sudden transitions between states of consciousness (Drab, 1981b). Interestingly, even in nonscientific popular books we may find data about abrupt transitions in NDEs. For example, in one of Raymond Moody's books citing historical accounts of NDEs, this fact appeared clearly stated (Moody, 1977).

An interesting feature of NDEs that could help in the construction of a general theory of alternate states of consciousness is the appearance of different states along well-defined temporal paths: outof-body experiences, tunnels, panoramic memory, simple and complex visual hallucinations, and so on. Therefore, it would be of great heap this line of work if researchers possessing NDE data banks produced a detailed study including the elements appearing in each experience, together with their temporal order of appearance. This information, coupled with analogous results for out-of-body experiences and other alternate states of consciousness, will allow the construction of subspaces of $\Gamma$ and $\Theta$. We urge near-death researchers to provide this kind of information.

These arguments imply that our neurobiological model for NDEs must be considered as a special case in which the elements appeared in a certain order (Saavedra-Aguilar and Gómez-Jeria, 1989a, 1989b). Further elaboration of our model is dependent upon the determination of the different alternate states appearing in NDEs, together with their order of appearance, and the neurobiological modeling of each alternate state (see for example Gómez-Jeria and Saavedra- 
Aguilar, 1994). The concept of brain modules could help in this task (Gazzaniga, 1985).

NDE reports are always subsequent to the experience itself; this fact hinders the measurement of the variables needed to locate the corresponding hypervolume in $\Gamma$. Nevertheless, the similarity among some aspects of NDEs and those of other alternate states of consciousness, together with the clear dependence of consciousness upon brain functioning, allows us to infer the kind of participation of some cerebral structures in these phenomena.

On the other hand, the lack of knowledge of all the variables defining the $\Theta$ space makes the location of the hypervolume(s) corresponding to the different NDE stages and the formal comparison of them with alternate states of consciousness difficult. For these reasons it is not possible even to try to deduce the mathematical transformation among the movements of the image points in $\Gamma$ and $\Theta$. Nevertheless, with the recent use of positron emission tomography and magnetic resonance imaging, the first functional brain/consciousness relationships are beginning to appear (Posner, 1993). It seems to us that in the next few years the study and analysis of $\Gamma / \Theta$ relationships will undergo very rapid development.

There is another problem appertaining to all consciousness states: the lack of an instantaneous relationship between brain state and consciousness state. As all consciousness states are the result of a brain state, they must follow them in time. This is so because a certain amount of time is needed between the establishment of a neuronal configuration and the appearance of some content in the field of consciousness (Gurwitsch, 1979).

Other problems that need attention are the way in which the brain generates material later reaching the field of consciousness through symbolic imagery and the unconscious actions that are the product of neuronal activity.

We suggest that this field of research is marvelous enough without invoking souls. Science does not need a paradigm shift to deal with NDE data (Serdahely, 1990). This is only a pretext to insert into science personal beliefs that destroy its objectivity and rationality. If anything is needed, it is a shift to rational thinking. William Serdahely (1990) mentioned the rise of "exotic" experiences and the resistance, suppression, and skepticism of scientists working under the present scientific paradigm.

In this respect we agree that the number of people undergoing or admitting "exotic" experiences is growing. It is also clear that the 
number of people under psychiatric treatment and the number of automobile crashes are growing. The real problem is why all these numbers (and others) are growing. Maybe factors such as the psychopathology of urban life, internal conflicts of daily life, growing anxiety in a stressful way of life, and the transformation of our societies into what Marshall McLuhan (McLuhan and Powers, 1992) called "the global village" should be considered.

We have two counterexamples to suggest that a paradigm shift is unnecessary. In the 1960 s a lot of people began to experiment with mysticism, meditation, Occidentalized Oriental religions, psychedelic drugs, and so on. What did science do? It provided us with social psychologists, theories about social learning, humanistic psychology, and so on. In the 19th century, despite the acknowledgment of fraud, spiritism continued to be practiced. What did science do? Without a paradigm shift it provided us with the contributions of Sigmund Freud and Pierre Janet. Paradigm shift is most probably related to the necessity of holding a critical quantity of data accessible to all observers that cannot be explained by the present models and theories. A change of paradigm cannot be invoked for data that are suspect, to say the least, and/or accessible only to "privileged" individuals.

Within this view, models that contradict physical reality (see Lundhal, 1993a, 1993b), make an appeal to forms of bioenergy so subtle we cannot even measure them (Ring and Rosing, 1990), insert loose words such as telepathy (Becker, 1991), or mention visionary encounters happening only "inside the head" must be discarded. We must also remember that the appeal to "other dimensions" is classical in pseudoscientific writings: it is the spatial equivalent of "unknown forces" or "unknown energies" (Becker, 1990; Gliksman and Kellehear, 1990; Walker, Serdahely, and Bechtel, 1991).

Finally, we would like to comment briefly on two studies of NDEs that are of great interest for model creation. In the first one, Mori Insinger (1991) cited sociologist William Thomas's statement that "If men define situations as real, they are real in their consequences" (Thomas and Thomas, 1928, p. 572; cited in Insinger, 1991, p. 141). This is certainly a true fact explaining not only the $a$ posteriori impact of an NDE upon a person, but also political and religious persecutions, concentration camps, and mass murder. In the second study, Bruce Greyson found in a sample of suicide attempters that 
The group reporting NDEs and the group not reporting NDEs did not differ from each other in any parameters measuring psychopathology, religious background, or expectations of death and dying. (1991, p. 183)

He suggested that this finding contradicted the hypothesis that NDEs represent fantasies based on religious teachings. This is consistent with our neurobiological model for NDEs (Gómez-Jeria and Saavedra-Aguilar, 1994; Saavedra-Aguilar and Gómez-Jeria, 1989a, $1989 \mathrm{~b}$ ), which is not dependent upon religious belief, although subsequent verbal reports of these experiences may be. Nevertheless, we would like to suggest that there is another factor that was not taken into account: the subliminal one. In fact, subliminal influences such as television, cinema, personal readings, newspapers, and other environmental influences could effectively contribute to shaping subsequent verbal reports despite the individual's religious beliefs or lack of them.

\section{References}

Andrews, P. (1992). An ape from the south. Nature, 356, 106.

Arensburg, B., and Tillier, A.-M. (1990). Le language des Neandertaliens. La Recherche, 21, 1084-1086.

Armstrong, D. M. (1973). Epistemological foundations for a materialist theory of the mind. Philosophy of Science, 40, 178-193.

Arnette, J. K. (1992). On the mind/body problem: The theory of essence. Journal of Near-Death Studies, 11, 5-18.

Barbas, H., and Pandya, D. N. (1989). Architecture and intrinsic connections of the prefrontal cortex in the Rhesus monkey. Journal of Comparative Neurology, 286, 353-375.

Beck, B. B. (1974). Baboons, chimpanzees and tools. Journal of Human Evolution, 3, 509-516.

Becker, C. B. (1990). Extrasensory perception, near-death experiences, and the limits of scientific knowledge. Journal of Near-Death Studies, 9, 11-20.

Becker, C. B. (1991). Over my dead body there is an ideal utopia: Comments on Kellehear's paper. Journal of Near-Death Studies, 10, 97-106.

Beynon, A. D., and Dean, M. C. (1988). Distinct dental development patterns in early fossil hominids. Nature, 335, 509-514.

Bourguignon, E., and Evascut, T. (1977). Altered states of consciousness within a general evolutionary perspective: A holocultural analysis. Behavior Science Research, $12,197-216$.

Brain, C. K., and Sillen, A. (1988). Evidence from the Swartkrans cave for the earliest use of fire. Nature, 336, 464-466.

Bunge, M. (1980). The mind-body problem: A psychobiological approach. London, England: Pergamon.

Cann, R. L., Stoneking, M., and Wilson, A. C. (1987). Mitochondrial DNA and human evolution. Nature, $325,31-36$. 
Cavalli-Sforza, L. L., Piaza, A., Menozzi, P., and Mountain, J. (1988). Reconstruction of human evolution: Bringing together genetic, archeological, and linguistic data. Proceedings of the National Academy of Sciences, 85, 6002-6006.

Connolly, J. C. (1950). External morphology of the primate brain. Springfield, IL; Charles $\mathrm{C}$ Thomas.

Conroy, G. C., Pickford, M., Senut, B., Van Couvering, J. and Mein, P (1992). Otavipithecus namibienses, first Miocene hominoid from southern Africa. Nature, 356, 144-148.

Conroy, G. C., Vannier, M. W., and Tbbias, P. V. (1990). Endocranial features of Australopithecus africanus revealed by 2- and 3-D computed tomography. Science, 247, 838-841.

Crosby, E. C. (1982). Telencephalon of primates. In E. C. Crosby and H. N. Schmitzloin (Eds.), Comparative correlative neuroanatomy of the vertebrate telencephalon (pp. 727-729). New York, NY: Macmillan.

Drab, K. J. (1981a). The tunnel experience: Reality or hallucination? Anabiosis: The Journal of Near-Death Studies, 1, 126-152.

Drab, K. J. (1981b). Unresolved problems in the study of near-death experiences: Some suggestions for research and theory. Anabiosis: The Journal of Near-Death Studies, $1,27-43$.

Fischer, R. (1971). A cartography of the ecstatic and meditative states. Science, 174, 897-904.

Foley, R. A., and Lee, O. C. (1989). Finite social space, evolutionary pathways, and reconstructing hominid behavior. Science, 243, 901-906.

Fouts, R. S. (1974). Language: Origins, definitions and chimpanzees. Journal of $\mathrm{Hu}$ man Evolution, 3, 475-482.

Gallup, G. G. (1968). Mirror-image stimulation. Psychological Bulletin, 70, 782-793.

Gallup, G. G. (1970). Chimpanzees: Self-recognition. Science, 167, 86-87.

Gallup, G. G. (1977). Self-recognition in primates: A comparative approach to the bidirectional properties of consciousness. American Psychologist, 32, 329-338.

Garber, H. J., Ananth, J. V., Chiu, L. C., Griswold, V. J., and Oldendorf, W. H. (1989). A nuclear magnetic resonance study of obsessive-compulsive disorder. American Journal of Psychiatry, 146, 1001-1005.

Gazzaniga, M. S. (1993). The social brain. New York, NY: Basic Books.

Gazzaniga, M. S., Holtzman, J. D., and Smylie, C. S. (1987). Speech without conscious awareness. Neurology, 7, 682-685.

Gibbons, A. (1993). Pleistocene population explosions. Science, 262, 27-28.

Gibson. J. J. (1966). The senses considered as perceptual systems. Boston, MA: Houghton-Mifflin.

Gliksman, M. D., and Kellehear, A. (1990). Near-death experiences and the measurement of blood gases. Journal of Near-Death Studies, 9, 41-43.

Globus, G. G., Maxwell, G., and Savodnik, I. (Eds.). (1977). Consciousness and the brain. New York, NY: Plenum.

Gómez-Jeria, J. S. (1993). A near-death experience among the Mapuche people. Journal of Near-Death Studies, 11, 219-222.

Gómez-Jeria, J. S., and Saavedra-Aguilar, J. C. (1994). A neurobiological model for near-death experiences. II: The problem of recall of real events. Journal of NearDeath Studies, 13, 81-89.

Gray, J. A. (1987). The neuropsychology of anxiety. New York, NY: Oxford University Press.

Green, P., Hallett, S., and Hunter, M. (1983). Abnormal interhemispheric integration and hemispheric specialization in schizophrenics and high-risk children. In P. FlorHenry and J. Gruzelier (Eds.), Laterality and psychopathology (pp. 443-470). Amsterdam, The Netherlands: Elsevier. 
Greyson, B. (1991). Near-death experiences precipitated by suicide attempt: Lack of influence of psychopathology, religion, and expectations. Journal of Near-Death Studies, 9, 183-187.

Gurwitsch, A. (1979). El campo de la conciencia [The field of consciousness]. Madrid, Spain: Alianza.

Hill, A., Ward, S., Deinoi, A., Curtis, G., and Drake, R. (1992). Earliest Homo. Nature, 355, 719-722.

Ingvar, D. H. (1979). Hyperfrontal distribution of the cerebral grey matter flow in resting wakefulness: On the functional anatomy of the conscious state. Acta Neurologica Scandinavica, 60, 12-25.

Insinger, M. (1991). The impact of a near-death experience on family relationships. Journal of Near-Death Studies, 9, 141-181.

Irenaeus of Lyon (circa 180). Adversus haereses [Against heresies]. I: 9, 4.

James, W. (1984). Psychology: Briefer course. Cambridge, MA: Harvard University Press. (Original work published 1892.)

Jones, E. E. (1986). Interpreting interpersonal behavior: The effects of expectancies. Science, 234, 41-46.

Kiesler, C. A., and Pallak, M. S. (1976). Arousal properties of dissonance manipulations. Psychological Bulletin, 83, 1014-1025.

King, J. E., and Fobes, J. L. (1974). Evolutionary changes in primate sensory capacities. Journal of Human Evolution, 3, 435-443.

King, M.-C., and Wilson, A. C. (1975). Evolution at two levels in humans and chimpanzees. Science, 188, 107-118.

Lewin, R. (1991). La naissance de l'anthopologie moleculaire. La Recherche, 22, 1242 1251.

Linton, H. B., Langs, R. J., and Paul, I. H. (1964). Retrospective alterations of the LSD-25 experience. Journal of Nervous and Mental Disease, 138, 409-423.

Lundahl, C. R. (1993a). Near-death visions of unborn children: Indications of a preEarth life. Journal of Near-Death Studies, 11, 123-128.

Lundahl, C. R. (1993b). Otherworld personal future revelations in near-death experiences. Journal of Near-Death Studies, 11, 171-179.

MacLean, P. D. (1990). The triune brain in evolution. New York, NY: Plenum.

Maddison, D. R. (1991). African origin of human mitochondrial DNA reexamined. Systematic Zoology, 40, 355-363.

Marsh, C. (1977). A framework for describing subjective states of consciousness. In N. E. Zimberg (Ed.), Alternate states of consciousness (pp. 121-144). New York, NY: Free Press.

Mason, W. A. (1976). Environmental models and mental modes: Representational processes in the great apes and man. American Psychologist, 31, 284-294.

McCormick, D. A. (1989). Cholinergic and noradrenergic modulation of thalamocortical processing. Trends in Neurosciences, 12, 215-221.

McLuhan, M., and Powers, B. R. (1992). The global village: Transformations in world life and media in the 21st century. New York, NY: Oxford University Press.

Mercier, N., Valladas, H., Joron, J.-L., Reyss, J.-L., Lévêque, F., and Vandermeersch, B. (1991). Thermoluminiscence dating of the late Neanderthal remains from SaintCésaire. Nature, 351, 737-739.

Moody, R. A. (1977). Reflections on life after life. St. Simon's Island, GA: Mockingbird Books.

Mounin, G. (1974). Reviews. Journal of Linguistics, 10, 197-206.

Mounin, G. (1976). Language, communication, chimpanzees. Current Anthropology, 17, 1-21.

Moyà Solà, S., and Kohler, M. (1993). Recent discoveries of Dryopithecus shed new light on evolution of great apes. Nature, 365, 543-545. 
Oxman, T. E., Rosenberg, S. D., Schnurr, P. P., Tucker, G. J., and Gala, G. (1988). The language of altered states. Journal of Nervous and Mental Disease, 176, 401408.

Paul, I. H. (1964). The effects of a drug-induced alteration in state of consciousness on retention of drive-related verbal material. Journal of Nervous and Mental Disease, 138, 367-374.

Pearson, R., and Pearson, L. (1976). The vertebrate brain. New York, NY: Academic Press.

Posner, M. I. (1993). Seeing the mind. Science, 262, 673-674.

Raab, F. V. (1965). Of minds and molecules. Philosophy of Science, 32, 57-72.

Reiman, E. M., Fusselman, M. J., Fox, P. T., and Raichle, M. E. (1989). Neuroanatomical correlates of anticipatory anxiety. Science, 243, 1071-1074.

Ring, K., and Rosing, C. J. (1990). The Omega Project: An empirical study of the NDE-prone personality. Journal of Near-Death Studies, 8, 211-239.

Saavedra-Aguilar, J. C., and Gómez-Jeria, J. S. (1987). [Towards a neurobiological model of self-consciousness.] Revista Chilena de Neuropsiquiatria,. 25, 247-251.

Saavedra-Aguilar, J. C., and Gómez-Jeria, J. S. ( 1989a). A neurobiological model for near-death experiences. Journal of Near-Death Studies, 205-222.

Saavedra-Aguilar, J. C., and Gómez-Jeria, J. S. (1989b). Response to commentaries on "A neurobiological model for near-death experiences." Journal of Near-Death Studies, 7, 265-272.

Sanidos, F. (1969). Comparative architectonics of the neocortex of mammals and their evolutionary interpretation. Annals of the New York Academy of Sciences, 167, 404423.

Schrenk, F., Bromage, T. G., Betzler, C. G., Ring, U., and Juwayeyi, Y. M. (1993). Oldest Homo and Pliocene biogeography of the Malawi Rift. Nature, 365, 833-836.

Serdahely, W. J. (1990). Thomas Kuhn revisited: Near-death studies and paradigm shifts. Journal of Near-Death Studies, 9, 5-10.

Sidtis, J. J., Volpe, B. T., Holtzman, J. D., Wilson, D. A., and Gazzaniga, M. S. (1981). Cognitive interaction after staged callosal sections: Evidence for transfer of semantic activation. Science, 212, 344-346.

Simons, E. L. (1989). Human origins. Science, 245, 1343-1350.

Stanley, S. M. (1992). An ecological theory for the origin of Homo. Paleobiology, 18, 237-257.

Stephan, H., and Andy, O. J. (1969). Quantitative comparative neuroanatomy of primates: An attempt at a phylogenetic interpretation. Annals of the New York Academy of Sciences, 167, 370-387.

Stringer, C. B. (1990). The emergence of modern humans. Scientific American, 263, 68-74.

Stringer, C. B. (1992). Neanderthal dates debated. Nature, 356, 201.

Stringer, C. B., and Andrews, P. (1988). Genetic and fossil evidence for the origin of modern humans. Science, 239, 1263-1268.

Tart, C. T. (Ed.). (1969). Altered states of consciousness: A book of readings. New York, NY: Wiley.

Tart, C. T. (1972). States of consciousness and state-specific sciences. Science, 176, $1203-1210$.

Tart, C. T. (1977). Putting the pieces together: A conceptual framework for understanding discrete states of consciousness. In N. E. Zimberg (Ed.), Alternate states of consciousness (pp. 158-219). New York, NY: Free Press.

Thomas, W. I., and Thomas, D. S. (1928). The child in America. New York, NY: Knopf.

Valladas, H., Vandermeersch, B., and Bar-Yosef, O. (1988). L'evolution de l'homme: Les surprises du Proche-Orient. La Recherche, 10, 966-968.

Valle, R. S., and von Eckartsberg, R. (Eds.). (1981). The metaphors of consciousness. New York, NY: Plenum. 
Vigilant, L., Stoneking, M., Harpending, H., Hawkes, K., and Wilson, A. C. (1991). African populations and the evolution of human mitochondrial DNA. Science, 253, 1503-1507.

von Glasserfeld, E. (1974). Signs, communication, and language. Journal of Human Evolution, 3, 465-474.

Walker, A., Leakey, R. E., Harris, J. M., and Brown, F. H. (1986). 2.5-Myr Australopithecus boisei from west of Lake Turkana, Kenya. Nature, 322, 517-522.

Walker, B. A., Serdahely, W. J., and Bechtel, L. J. (1991). Three near-death experiences with premonitions of what could have been. Journal of Near-Death Studies, 9, 189 196.

Watanabe, M. (1989). The appropriateness of behavioral responses coded in post-trial activity of primate prefrontal units. Neuroscience Letters, 101, 113-117.

White, J. (Ed.). (1972). The highest state of consciousness. New York, NY: Anchor.

Wilkes, K. V. (1980). Brain states. British Journal of the Philosophy of Science, 31, 111-129.

Wolpoff, M. H. (1984). Evolution in Homo erectus: The question of stasis. Paleobiology, $10,389-406$.

Wolpoff, M. H., and Frazer, D. W. (1992). Neanderthal dates debated. Nature, 355, 200-201.

Wood, B. (1992a). Old bones match old stones. Nature, 355, 678-679.

Wood, B. (1992b). Origin and evolution of the genus Homo. Nature, 355, 783-790.

Yeni-Kanshian, G. H., and Benson, D. A. (1976). Anatomical study of cerebral asymmetry in the temporal lobe of humans, chimpanzees, and Rhesus monkeys. Science, 192, 387-389.

Zaehner, R. C. (1972). Zen, drugs and mysticism. New York, NY: Vintage Books.

Zimberg, N. E. (Ed.). (1977). Alternate states of consciousness. New York, NY: Free Press. 
